\title{
Publisher Correction: The transcriptional regulator HDP1 controls expansion of the inner membrane complex during early sexual differentiation of malaria parasites
}

Riward A. Campelo Morillo, Xinran Tong, Wei Xie (D), Steven Abel, Lindsey M. Orchard (D), Wassim Daher (D), Dinshaw J. Patel (D), Manuel Llinás (D), Karine G. Le Roch and Björn F. C. Kafsack (D)

Correction to: Nature Microbiology https://doi.org/10.1038/s41564-021-01045-0, published online 27 January 2022.

In the PDF version of this article initially published, Fig. 5 was a duplicate image of Fig. 4 . The correct image has now been included in the print and PDF versions of the article.

Published online: 8 February 2022

https://oi.org/10.1038/s41564-022-01082-3

๑ The Author(s), under exclusive licence to Springer Nature Limited 2022 